East African Medical Journal Vol. 80 No 10 October 2003

SPECTRUM AND OUTCOME OF CLINICAL DISEASES IN ADULTS LIVING WITH AIDS AT THE OGUN STATE UNIVERSITY TEACHING HOSPITAL S.A. Ogun, BSc, MBChB; (lfe), Cert.Neurol. (Lond), FWACP, O.O. Adelowo, MBBS, FMCP, FWACP (Int. Med.), Professor, O.B. Familoni, MBBS, FMCP, Senior Lecturer, O.B., Adefuye, MBBS, FWACP, Senior Lecturer, C. Alebiosu, MBBS; FWACP MISN, Senior Lecturer, A.E.A. Jaiyesimi, MBBS, FMCP, FWACP, (Int. Med) Professor, E.A.O. Fakoya, MD, Reader, B. Odusan, MBBS, FMCP, Senior Lecturer, O.L. Odusoga, MBBS, FWACS, Senior Lecturer, and O.O. Ola, MBBS, FWACP, Senior Lecturer, Department of Medicine, Ogun State University Teaching Hospital, Sagamu, Ogun State, Nigeria

Request for reprints to: Dr. S.A. Ogun, Department, of Medicine, Ogun State University Teaching Hospital, Sagamu, Ogun State, Nigeria

\title{
SPECTRUM AND OUTCOME OF CLINICAL DISEASES IN ADULTS LIVING WITH AIDS AT THE OGUN STATE UNIVERSITY TEACHING HOSPITAL
}

\author{
S.A. OGUN, O.O. ADELOWO, O.B. FAMILONI, O.B. ADEFUYE, C. ALEBIOSU, A.E.A. JAIYESIMI, \\ E.A.O. FAKOYA, B. ODUSAN, O.L. ODUSOGA and O.O. OLA
}

\begin{abstract}
Objectives: To evaluate the changing frequency of HIV/AIDS amongst medical admissions as well as the spectrum and outcome of clinical diseases among these patients.

Design: Retrospective study.

Setting: Tertiary hospital in Nigeria.

Participants: Two hundred and six People Living With AIDS (PLWA) admitted at the medical wards during the period 1992 to 2002.

Intervention: Treatment was symptomatic in all patients and where appropriate, specific treatment was administered for indicator diseases. Highly Active Anti-retroviral Therapy (HAART) was not used.

Main outcome measures: Mortality within six months of diagnosis.

Results: PLWA constituted $4.2 \%$ of all medical admissions. The frequency increased from $0 \%$ in 1992 to $7.6 \%$ in 2001 , and dropped to $5 \%$ by the year 2002 . Seventy patients (34\%) died within six months of diagnosis.

Results: This study has demonstrated an increasing frequency of HIV/AIDS amongst our medical in-patients from none in 1992 to $7.6 \%$ in 2001, and thereafter, a decline in 2002. We suspect that this decline could be a reflection of the health education on HIV, its increasing awareness and the widespread utilisation of effective control measures. Furthermore, the administration of highly active anti retroviral therapy (HAART) to a segment of PLWA in Sagamu by the community medicine department could be contributory.

Conclusion: A community based study would be needed to assess the efficacy or otherwise of these current control measures. The advent of saliva and urine tests for HIV detection would ease specimen collection and increase compliance and participation at the community level.
\end{abstract}

\section{INTRODUCTION}

HIV/AIDS is a leading cause of public health crises and the increasing incidence and prevalence continue to require a greater proportion of the limited financial, medical and human resources $(1,2)$. In Nigeria, the first case was reported in a sexually active 13 year old girl from Benue State in 1984 (3), and ever since, the incidence and prevalence have been on the increase. According to a recent seroprevalence data by the Ministry of Health, about 2.6 million Nigerians are said to be carrying the virus, the overall national prevalence being $5.8 \%$ (4).

The Ogun State University Teaching Hospital (OSUTH) is situated in Sagamu, a peri-urban town located about $50 \mathrm{~km}$ from either Lagos or Ibadan, with a population of about 50,000 (1992 census). Agriculture and trading are the major occupation of the residents. There are in addition, a large cement factory and a major petroleum depot with its attendant vibrant trailer and tanker presence as well as a booming sex trade involving the tanker drivers and the locals. The hospital is a tertiary health facility serving all towns in Ogun state as well as the adjoining parts of Lagos and Oyo states, and has 240 beds distributed amongst the various specialities with 40 in-patients beds for medical admissions; 20 for females and the same for males apiece. The bases for admission are usually the acute care needs of patients, the need for highly skilled management and the severity of the patients' illness as well as suitability for teaching and research (6). Patients are admitted mostly through the accident and emergency department, general out-patient and medical out-patient clinics.

This study was aimed at reviewing over a ten-year period the frequency of HIV/AIDS amongst medical in-patients in a teaching hospital as well as assessing the pattern of morbidity and mortality in these patients. 


\section{MATERIALS AND METHODS}

The case notes of all patients admitted on the medical wards of Ogun State Teaching Hospital, Sagamu from December 1992 to November 2002 were retrieved and those with HIV sero-positivity were reviewed. Only symptomatic (Group IV) HIV sero-positive patients were admitted and they all satisfied the WHO expanded clinical case definition for the diagnosis of AIDS in adult Africans (5). HIV screening was done amongst medical in-patients only when they presented with features of an AIDS related or defining conditions. Pre- and post-test counselling was also done (5). The screening was done by ELISA technique using Immunocomb and repeatedly reactive ELISA with two different kits was taken as confirmatory. Confirmatory test, CD4 count and viral load were not done, as there were no facilities at the time of study. The results of full blood count and differentials, ESR, VDRL, HBsAg, chest X-ray, sputum and stool microscopy (and AFB), culture and sensitivity Mantoux test and other appropriate ancillary investigations done for indicator diseases were recorded.

Patients were classified into upper, middle and lower social classes based on the British system classification (7). The upper social class included high professionals, managers, lawyers, business directors, while the middle class included lower professionals, teachers, social, skilled and clerical workers. The lower social class included semi-skilled workers, agricultural labourers, unskilled workers, domestic servants and casual workers.

Analyses of the patients' demographic characteristics, clinical features and results of investigations were done by standard statistical methods. Treatment was symptomatic in all patients and where appropriate, specific treatment was administered for indicator diseases. Highly Active Antiretroviral Therapy (HAART) was not used routinely for medical in-patients at the time of study. However, a segment of the PLWA in the community received HAART and formed part of a separate study (8).

\section{RESULTS}

A total of 4,879 patients (2,460 females and 2,419 males) were admitted to the medical wards over the study period out of which $206(4.2 \%)$ were PLWA. The frequency increased from $0 \%$ in 1992 to $7.6 \%$ in 2001 respectively, and dropped to $5 \%$ by the year 2002 (Table 1). Out of the 206 AIDS patients seen, 91 were HIV I and 11 positive, $102 \mathrm{HIV}-1$, and $13 \mathrm{HIV}-1 \mathrm{l}$ positive. There were 111 males and 95 females, giving a male: female ratio of $1.2: 1$. The age range was between 13 to 73 years with a mean of $43 \pm 4.2$ years and a peak in the 3rd decade (Figure 1).

Table 2, shows the demographic characteristics of the PLWA. One hundred and eighty three (89\%) patients belonged to the lower social class, of which 78 were long distance truck drivers/conductors (38\%), 58 were inter-state traders (28\%), 18 each were housewives or retired members of the armed forces $(9 \%)$. One hundred and thirty six $(66 \%)$ patients were married, $39(19 \%)$ were single, $24(11 \%)$ were divorcees, while the marital status of seven patients was not stated in the case notes. History of sexual exposure involving single or multiple partners was documented in 185 patients $(90 \%)$. Blood transfusion was a plausible predisposing factor in $25(12 \%)$ patients while no obvious predisposing factor was identified in 11 (5.5\%). Neither homosexuality nor intravenous drug use was reported in any of the subjects.

Figure 1

Pattern of age distribution of PLWA in Sagamu, Nigeria 
Table 1

Yearly frequency and age distribution amongst AIDS patients

\begin{tabular}{lllllllllllll}
\hline Year & $\begin{array}{l}1992 \\
\text { Dec }\end{array}$ & 1993 & 1994 & 1995 & 1996 & 1997 & 1998 & 1999 & 2000 & 2001 & 2002 & Total \\
& & & & & & & & & & & &
\end{tabular}

\begin{tabular}{|c|c|c|c|c|c|c|c|c|c|c|c|c|}
\hline Age (yrs) & 50 & 182 & 418 & 862 & 658 & 251 & 408 & 278 & 578 & 591 & 603 & 4879 \\
\hline $10-19$ & - & - & - & 1 & 1 & 3 & - & - & 2 & 1 & 0 & 8 \\
\hline $20-29$ & - & - & 1 & 4 & 6 & 5 & 18 & 8 & 14 & 20 & 10 & 86 \\
\hline 30-39 & - & 2 & 3 & 6 & 6 & 6 & 9 & 7 & 10 & 14 & 11 & 74 \\
\hline $40-49$ & - & - & 3 & 1 & 2 & - & 1 & 2 & 4 & 4 & 6 & 23 \\
\hline $50-59$ & - & - & - & - & - & 1 & 1 & - & - & 4 & 2 & 8 \\
\hline 60-69 & - & - & - & - & - & 3 & - & - & - & 1 & 1 & 5 \\
\hline 70 & - & - & - & - & - & - & - & - & - & 1 & 0 & 2 \\
\hline Total (\%) & $0(0)$ & $2(1.1)$ & $7(1.7)$ & $12(1)$ & $15(2)$ & $18(7.2)$ & $30(7.4)$ & $17(6.2)$ & $30(5.2)$ & $45(7.6)$ & $30(5)$ & $206(4.2)$ \\
\hline $\begin{array}{l}\text { Yearly } \\
\text { Mortality }\end{array}$ & $0(0)$ & $2(100)$ & $4(57)$ & $6(50)$ & $5(33)$ & $5(28)$ & 11(37) & $6(35)$ & $10(33)$ & 13(29) & $8(27)$ & $70(34)$ \\
\hline
\end{tabular}

Females $=2640 ;$ Males $=2419$

Table 2

Demographic characteristics of the PLWA

\begin{tabular}{ll}
\hline Characteristic & PLWA (n=206) \\
\hline Age (years) & $43 \pm 4.2$ \\
Sex Male & 111 \\
Female & 95 \\
Social Class & \\
High & 0 \\
Middle & $23(11 \%)$ \\
Low Occupation & $183(89 \%)$ \\
Occupation & \\
Long distance drivers & $78(38 \%)$ \\
Inter-state traders & $58(28 \%)$ \\
Housewife & $18(9 \%)$ \\
Retired soldier & $18(9 \%)$ \\
Others & $34(16 \%)$ \\
Marital Status & \\
Single & $39(19 \%)$ \\
Married & $136(66 \%)$ \\
Divorced & $24(11 \%)$ \\
Unknown & $7(4 \%)$ \\
\hline
\end{tabular}

Table 3 shows the clinical features of PLWA. Weight loss and chronic weakness were universal in all the patients. Chronic cough and diarrhoea each was found in 163 (79\%) and fever in 144 (70\%) cases. Extensive dermatitis (mainly pityriasis vesicolor) or oral candidosis each was found in 62 (30\%) cases. Persistent generalised Iymphadenopathy (PGL) or herpes zooster or chicken pox each was found in $12(6 \%)$ patients and herpes simplex in six (3\%) patients. These entities were not mutually exclusive. Anaemia was seen in 185 (90\%) patients with haematocrit in the range of 8-29\%. Normal white blood cell count was found in $177(86 \%)$ patients while 23 $(11 \%)$ had leucocytosis and six $(3 \%)$ had leucopenia.

The commonest indicator disease was mycobacterium tubercle infection found in $163(79 \%)$ of the patients. One hundred and thirty two (80\%) were Koch's disease, 13 (8\%) had disseminated TB, nine (5.5\%) had TB meningitis, eight (4.9\%) had abdominal TB and one $(0.6 \%)$ Pott's disease. Oropharyngeal candidosis was found in $25(12.1 \%)$ while HIV vacuolar myelopathy or HIV associated nephropathy each was found in nine subjects (4.5\%). Toxoplasma encephalitis was found in six $(2.9 \%)$ patients and AIDS dementia complex in five $(2.4 \%)$ patients.

Seventy patients (34\%) died within six months of diagnosis in the hospital, and these were attributed to progression of HIV disease or severe inter-current infection. Progressive yearly decline in mortality was observed (Table 1). Seventy eight (38\%) patients were discharged to the Medical/Community medicine outpatient clinic for follow-up, 27(13\%) discharged themselves against medical advice and $31(15 \%)$ were lost to follow-up. 
Table 3

Clinical characteristics of PLWA

\begin{tabular}{ll}
\hline Characteristic & No. (\%) \\
\hline Haemogram & \\
Anaemia $(8-29 \%)$ & $185(90)$ \\
Normal white cell count & $177(86)$ \\
Leucocytosis & $23(11)$ \\
Leucopenia & $6(3)$ \\
AIDS related complex (ARC) * & $62(30)$ \\
Oral candidosis & $62(30)$ \\
Generalised dermatitis (P.vesicolor) & $12(6)$ \\
H. zooster & $12(6)$ \\
Chicken - pox & $12(6)$ \\
Persistent glandular Iymphadenopathy & $6(3)$ \\
H. simplex & \\
AIDS Indicator Diseases / Defining conditions * & $206(100)$ \\
Weight loss and generalised weakness & $144(70)$ \\
Fever- continous/intermittent & $163(79)$ \\
Diarrhoea & $163(79)$ \\
Tuberculosis & $25(12.1)$ \\
Oro-pharyngeal candidosis & $9(4.5)$ \\
HIV Vacuolar Myelopathy & $9(4.5)$ \\
HIV Associated Nephropathy & $6(2.9)$ \\
Toxoplasma encephalitis & $5(2.4)$ \\
AIDS dementia complex & \\
Mortality (Within six months) & $70(34)$ \\
Cause of Death & $55(79)$ \\
Progression of HIV disease / wasting & $15(21)$ \\
Chronic diarrhoea & \\
\hline
\end{tabular}

* These entities were not mutually exclusive

\section{DISCUSSION}

The frequency of AIDS of $4.2 \%$ amongst medical in-patients in a peri-urban setting gives cause for concern. This frequency is comparable to those of acute viral hepatitis septicaemia haemoglobinopathy and neuropathies, but higher than tetanus and meningitis as causes of medical admission amongst adults in sagamu (6). This report however contrasts sharply with the frequency of over $50 \%$ of the medical admissions in Uganda (9). The rising frequency of HIV/AIDS from $0 \%$ to $7.6 \%$, albeit with subsequent decline to $5 \%$ towards the end of the study, reflects the global increase in the prevalence visa-vis heightened physicians' awareness and easy availability of HIV screening tests. In a series from the Lagos University Teaching Hospital, a rising frequency from $10 \%$ to $36 \%$ over a five-year period (1992 -1996) amongst adults AIDS patients was also reported (10). However, the decline from $7.6 \%$ in 2001 to $5 \%$ in 2002 could also reflect the recent conviction and concern at the state and national levels of its increase. There is a strong will to counteract its spread in the country, as several health education programmes and jingles on preventive strategies are common occurrences in the country today. Furthermore, the introduction of HAART to a segment of the PLWA in the community could be contributory. Analysis of this subset of PLWA formed part of another study (8).
Majority of the patients in this study presented in the 3rd decade of life and this is similar to earlier reports $(1,11)$. Compared to our earlier observation of a peak in the 4th decade (12), the present observation suggests earlier occurrence as the epidemic spreads. This peak frequency in the reproductive age group supports the significant risk associated with sexual activity as majority $(90 \%)$ of the patients had positive history of casual sex or multiple sexual partners, $89 \%$ of whom were heterosexuals. This supports the view by several authors (11-15) that HIV is transmitted essentially by the heterosexual route in Africa, a continent where homosexualism is rare (2). The high prevalence of ulcerative and non-ulcerative STDs in Africa has been alluded as co-morbidity for this rampant heterosexual transmission (9).

The high frequency of the disease among inter-state traders, long distance truck drivers/conductors or their wives is not surprising since they unavoidably stay away from home for long periods and may thus patronise commercial sex workers in whom HIV infection rates of $20-50 \%$ have been reported $(11,16)$. Majority $(66 \%)$ of the patients were married. This is not unexpected since they could be more sexually active. This would suggest that frequent extramarital sexual activities in married couples could be an additional risk factor to HIV infection. Twelve per cent of the patients had blood transfusion as 
a plausible predisposing factor. At the Lagos University Teaching Hospital (LUTH), $10 \%$ of adult AIDS patients also had this as the plausible predisposing factor (10). This reflects inadequacy of HIV screening facilities in most blood banks in the country. However, negative screening of infected donors who are antibody negative during the window period has been reported (17). HIV detection by viral culture, antigen and genome detection using polymerase chain reaction would be useful in identifying such seronegative donors. At the moment, blood transfusion would continue to be a risk factor in our country because of unavailability of these facilities. In $5.5 \%$ of the study group, no risk factor was identified, and in none of the patients was intravenous drug abuse reported. This observation in our study may reflect incomplete or inaccurate case-note recording in a retrospective study or could suggest an unidentified risk factor in our environment as yet. Although the number of unidentified or "cryptogenic" risk factor $(5.5 \%)$ is rather small for definitive conclusions, it is higher than the $0.2 \%$ reported in the literature (18).

The high frequency $(79 \%)$ of tuberculosis among the subjects is similar to a previous report (19), although a lower frequency $(15 \%)$ was reported at LUTH (10). The symptomatology of TB and AIDS are similar and HIV screening of all TB patients has been suggested in TB endemic areas. Oral candidosis is commoner in Africans than in the Caucasians $(14,15)$. The frequency of $30 \%$ reported in this study is higher than a frequency of $6.6 \%$ reported in a similar study in Nigeria (10). Generalised dermatitis was also found in $30 \%$ of the cases of which extensive pityriasis versicolor appears commoner than chicken-pox, herpes zooster or simplex infections. This has also been observed amongst AIDS patients at LUTH and the University College Hospital, Ibadan (personal communication: OY; OB).

The most consistent laboratory finding was anaemia, which was documented in $90 \%$ of the patients. Leucopenia with Iymphopenia documented by several authors $(2,20)$ was uncommon in our environment and occurred only in $3 \%$ of the patients. The significance of this finding in our environment is as yet unclear as normal Nigerians have relatively low white blood cell count (21). The prognosis in the patients was poor as $34 \%$ of the patients were dead within six months of diagnosis. This is comparable to the $50 \%$ mortality within one year of diagnosis in most reports $(8,14,16)$. The high mortality in this study is not surprising as all the admitted HIV seropositive patients had AIDS indicator diseases and needed acute care. Furthermore, the observed progressive decline from $100 \%$ mortality in 1993 to $27 \%$ in 2002 supports the current view that HIV/AIDS is a chronic illness rather than a death sentence; and that with the advent of newer antiretrovirals with convenient dosing regimen, a promising outlook continues to await PLWA.

In conclusion, this study demonstrated a rising frequency of HIV/AIDS as a cause of admission and deaths amongst medical in-patients in a tertiary health institution, albeit a recent decline was recorded towards the end of the study.
This is ominous. It is hoped that a community based study may indicate the seriousness of this infection and reflect the efficacy or otherwise of current control measures. The advent of saliva and urine tests for HIV detection would ease specimen collection and increase compliance and participation at the community level. This would reduce cost and make a community based study more feasible.

\section{REFERENCES}

1. Peter, P., and Jeffrey, H . AIDS in the world. Redefining the global HIV/AIDS pandemic, Yokohama, 5 August, 1994. Amanda, M

2. Amanda, Mocroft, AIDS 1996;10:1057-1065.

3. Federal Ministry of Health of Nigeria. Annual publication. 1995:25-30.

4. Federal Ministry of Health. National AIDS/STD control programme. $2001 \mathrm{HIV/SYPHILIS} \mathrm{sentnel} \mathrm{sero-prevalence} \mathrm{study}$ in Nigeria. Technical report, 2001.

5. Centre for Disease Control. Revised classification system for HIV infection and expanded case definition for AIDS among adolescents and adults. Morb. Mortal. Wkly. Rep. 1992; 41: $1-19$.

6. Ogun, S.A., Adelowo, O.O., Familoni, O.B., Jaiyesimi, A.E., and Fakoya, A. Pattern and outcome of medical admissions and deaths in Ogun State Teaching Hospital, Sagamu. - A three year review. West Afr. Med. J. 2000; 19:309.

7. Alakija, W. Essentials of Community Health, Primary Health Care and Health Management. AMBIK publication. Medical Sociology Chapter. 2000; 7: 88.

8. Ogun, S.A., Boyle, B.A., Lytton, J., et al. The starfish project: A successful pilot treatment programme using recovered antiretrovirals in South West Nigeria. Nig. Med. Pract. 2002; 42: 37-39.

9. Tembo, G., Friesan, H., Aslimwe, O., Masu, R., and Nasmara,W. Bed occupancy due to HIV/AIDS in an urban Hospital Medical ward in Uganda. AIDS. 1994; 8:1169-1171.

10. Akinsete, I., Okany, C. C., and Akanmu, A. S. Spectrum of clinical diseases in HIV infected adults at the Lagos University Teaching Hospital - A five year experience (1992-1996). Afr. J. Med. Sci. 1998 (in press)

11. Granje, H.S., Joubert, G., Muir, A., Chapman, R.D., and Diveall, P. B. Prevalence of vaginitis; syphilis and HIV infection in women in the Orange free State. South Afr. Med. J. 1994; 9: 602-605.

12. Ogun, S.A., Adelowo, O.O., Familoni, O.B., Jaiyesimi, A.E., and Fakoya, A.E. Frequency and outcome of HIV/AIDS in a teaching hospital-a 5 year review. Nigeria J. Hosp. Med. 1999; 9:177-179.

13. Mhalu, F. S. Inter- relationship between HIV infection and other sexually transmitted diseases. East Afr. Med. J. 1990; 76: 512-517.

14. Ankrah, T.C., Roberts, M.A., Antwi, P., Atubrah, M.P., Bawarah, P.P., and Kotoh, S. The African AIDS case definition and HIV serology in medical in patients at Komfo Anokye Teaching Hospital; Kumasi, Ghana. West Afr. J. Med. 1994; 13:98-101.

15. Prual, A., Chacko, S., and Koch, W. Sexual behaviour, AIDS and poverty in sub-Saharan Africa. Int. J. STD - AIDS. 1991; 2:1-9.

16. Barkey, S., Nasmara, W., Okware, S., Downing, R., and Konde, C. J. AIDS and HIV infection in Uganda. AIDS. 1990; 4:12371242

17. Mortimer, P.P. The virus and the tests. Brit. Med. J. 1987; 294:1602-1605.

18. Dunn, D., Newell, M: Ades, A and Peckham, C. Risk of HIV trasmission through breast feeding. Lancet. 1994; 340:585-588.

19. De-Cock - K . M.; Sara B; Cauliboly I. M; and Lucas S. B. TB and HIV infection in sub-Saharan Africa. J. Amer. Med. Ass. 1992; 268:1581-1587.

20. Mohammed I. and R. M. Joshi AIDS - A review. Nig. Med. Practitioner. 1984; 8:2.

21. Akinyanju, O., and Grossman, A.S., Leucocyte counts in healthy Nigerians. Nig. Med. J. 1973; 3:95-99. 